\title{
Consumption of Pt Anode in Phosphoric Acid
}

\author{
Nobuyuki KAMIYA*, Kenta URATA, Naobumi MOTOHIRA and Ken-ichiro OTA
}

Received June 6, 1997 ; Accepted August 25, 1997

Consumption of $\mathrm{Pt}$ anode was investigated in phosphoric acid of various concentration. In 30 $70 \mathrm{wt} \%$ phosphoric acid, Pt dissolved at the rate of $19 \mu \mathrm{gcm}^{-2} \mathrm{~h}-1$. On the other hand, in $85 \mathrm{wt} \%$ phosphoric acid, the amount increased to $0.91 \mathrm{mgcm}^{-2} \mathrm{~h}^{-1}$ which is ca. 180 and 1800 times as much as in $1 \mathrm{M}$ sulfuric acid and $1 \mathrm{M}$ alkaline solution, respectively.

In the diluted phosphoric acid solution, the Pt surface was covered with $\mathrm{Pt}$ oxides during the electrolysis, which would prevent the surface from corrosion. However, in the concentrated phosphoric acid, no such oxide surface was observed. Concentrated phosphoric acid might form stable complex with $\mathrm{Pt}$ species, therefore the uncovered bare $\mathrm{Pt}$ surface is situated in the serious corrosion condition under the high overvoltage and $\mathrm{Pt}$ would dissolve into the solution directly instead of forming the $\mathrm{Pt}$ oxides.

\section{INTRODUCTION}

Among various kinds of fuel cells that have been studied and developed hitherto, the phosphoric acid fuel cell would be most promising and has now widely been tested for commercial use 1 ). However, in the course of commercialization, far more longer life time and lower cost are desired. One reason that lowers the cell life time and characteristics is the reduction of the surface area of the catalyst under the corrosion of the supporting carbon materials. Under the operation of the phosphoric acid fuel cell, $\mathrm{Pt}$ catalyst dissolves into the electrolyte and the dissolved Pt species deposits or moves on the surface of the electrode. Therefore, the size of the Pt particles grows larger and the specific surface area decreases 2 ).

Consumption of $\mathrm{Pt}$ anode in sulfuric acid aqueous solution was reported ${ }^{3}$ ) and the characteristics of the $\mathrm{Pt}$ species were well studied 4 ). On the contrary, there has been few data reported on the corrosion in the phosphoric acid aqueous solution 2,5).

From this point of view, consumption of $\mathrm{Pt}$ anode in the phosphoric acid media has been studied and the

Department of Energy Engineering, Yokohama National University (79-5 Tokiwadai, Hodogaya-ku, Yokohama 240 Japan)

Key Words; Consumption of Pt Anode, Phosphoric Acid, Fuel Cell mechanism of dissolution was discussed. From these data, the characteristic of $\mathrm{Pt}$ anode in the concentrated phosphoric acid can be deduced.

\section{EXPERIMENTAL}

Platinum wires of which diameter and geometric surface area were $0.3 \mathrm{~mm}$ and $1 \mathrm{~cm}^{2}$, respectively, were wound in a coil shape and served for anodic electrolyses. The test $\mathrm{Pt}$ electrode was hung up on a $\mathrm{Pt}$ electrode holder and after the electrolyses, the electrode was detached from the holder. The used $\mathrm{Pt}$ wires were often used repeatedly unless their surface were seriously corroded. Although the surface of a new platinum wire is smooth, it becomes rather rough by the electrolysis. Therefore, before each electrolysis, both new and used wires were dipped in a hot aqua regia solution for $30 \mathrm{sec}$ in order to keep the surface condition constant. The dipping treatment made the surface of both samples to be the same and the roughness factor was around 2.

Junsei Chemical Co.'s analytical grade $97 \mathrm{w} t \%$ sulfuric acid and guranteed reagent grade $85 \mathrm{wt} \%$ phosphoric acid were dissolved in ultra pure water that passed through a Millipore filter and were served for electrolyses. The electrolyte was deaerated by passing $\mathrm{N}_{2}$ gas through the solution and the electrolyses were performed under the agitated condition. The temperature was kept constant in a water bath to be 
$400^{\circ} \mathrm{C}$. The consumption of the electrodes was examined under the constant current electrolysis. The amount of the consumed Pt was determined by weighing the electrode before and after the electrolysis on a semimicrobalance. Here the consumption of $\mathrm{Pt}$ was considered to occur due to two ways, i.e., one is to dissolve into the electolyte as ions or complexes and another is to degrade as the highly oxidized platinum oxide (this oxide is called the $\mathrm{Pt}$ oxide hereafter). This oxide is soluble in a hot hydrochloric acid. In this case, the amount of $\mathrm{Pt}$ in the $\mathrm{Pt}$ oxide was determined by a dithizone-benzene method 6,7).

The overvoltage of the electrodes for Tafel 's plots was obtained by using a current interrupting method in order to eliminate the IR drop.

\section{RESULTS AND DISCUSSION}

3.1 Voltammograms of $P t$ in various concentration of $\mathrm{H}_{3} \mathrm{PO}_{4}$

Figure 1 shows the voltammograms of $\mathrm{Pt}$ in $1 \mathrm{M}$ $\mathrm{H}_{2} \mathrm{SO}_{4}$ (a), and 30 (b) and $85 \mathrm{wt} \%$ (c) of phosphoric acid solution. In the diluted phosphoric acid solution, i.e., $30 \mathrm{wt} . \%$, the voltammogram is almost the same as that observed in $1 \mathrm{M}$ sulfuric acid solution. The shape of the voltammograms taken at 50 and $70 \mathrm{wt} \%$ is also the same as that of $30 \mathrm{wt} \%$. The quantity of electricity for hydrogen adsorption and desorption in the lower potential region, is nearly the same as in other solutions at different concentration. However, the quantity of electricity for the oxygen adsorption (or formation of $\mathrm{PtO}$ ) at 0.8-1.5 V vs. RHE and the reduction at $0.9-0.7 \mathrm{~V}$, decreases with the increase of the concentration as shown in Fig. 1. Figure 2 shows the dependence of the charge for formation and reduction of $\mathrm{PtO}$ as well as the charge for desorption of $\mathrm{H}_{\mathrm{ad}}$ on the concentration of phosphoric acid. In this figure, the vertical axis indicates the ratio of the charge at each concentration to that in $30 \mathrm{wt} \%$ solution. From the charge for hydrogen desorption from $\mathrm{Pt}$ surface taken at $1 \mathrm{M} \mathrm{H}_{2} \mathrm{SO}_{4}$ solution, the roughness factor (R.F.) of the surface was determined to be 2.31. In 30wt\% solution, the charge for desorption of hydrogen was nearly the same as that obtained in $1 \mathrm{M} \mathrm{H}_{2} \mathrm{SO}_{4}$. From Fig. 2, it is shown that the quantity of electricity for desorption of $\mathrm{H}_{\mathrm{ad}}$ does not change much with increase of the concentration. Opposite to the small change for $\mathrm{H}_{\mathrm{ad}}$, the charge for formation and reduction of PtO decreases much with increase of the concentration. Hydrogen adsorption

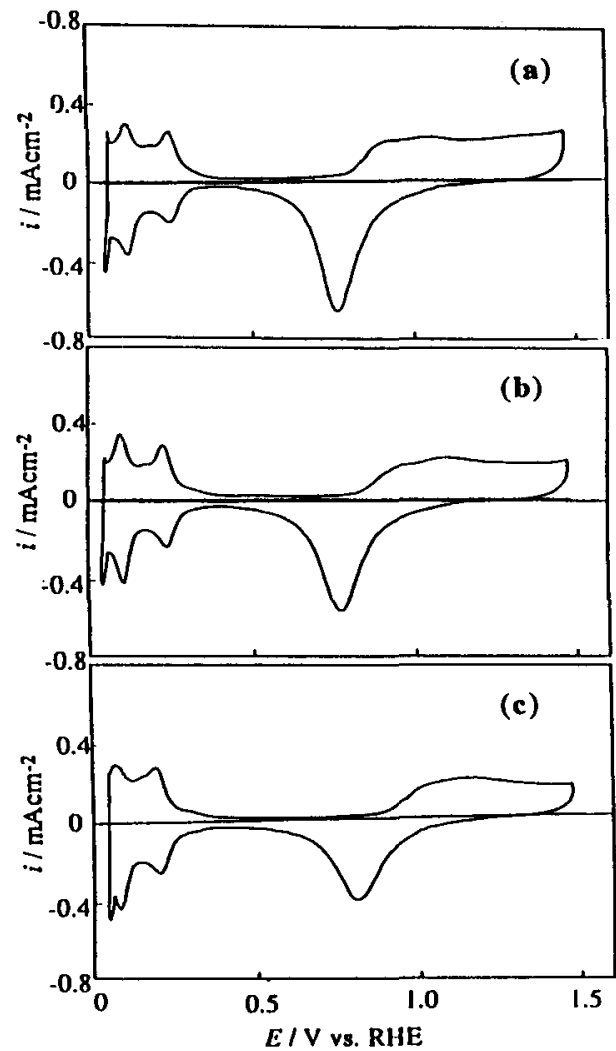

Fig.1 Voltammograms of $\mathrm{Pt}$ in $\mathrm{H}_{2} \mathrm{SO}_{4}$ and $\mathrm{H}_{3} \mathrm{PO}_{4}$ solution.

(a) $1 \mathrm{M} \mathrm{H}_{2} \mathrm{SO}_{4}$, (b) $30 \mathrm{wt} \% \mathrm{H}_{3} \mathrm{PO}_{4}$, (c) $85 \mathrm{wt} \% \mathrm{H}_{3} \mathrm{PO}_{4}$

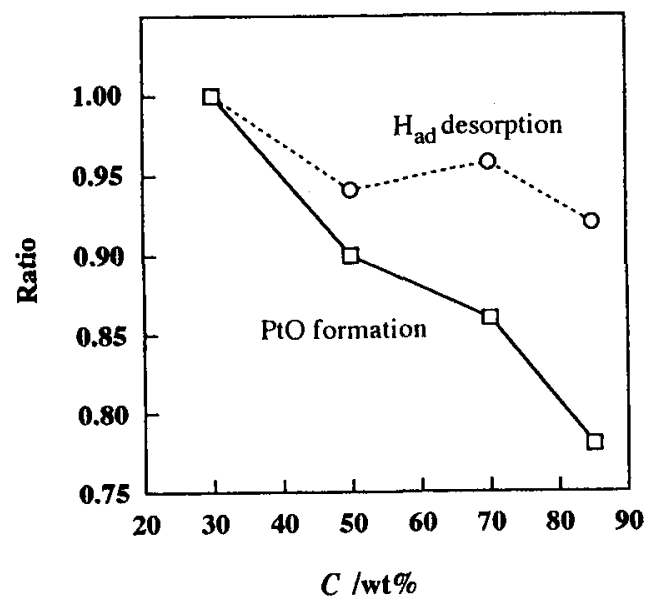

Fig. 2 Relation between the ratio of the quantity of electricity for desorption of $\mathrm{H}_{\mathrm{ad}}$ and formation of $\mathrm{PtO}$ and conc. of $\mathrm{H}_{3} \mathrm{PO}_{4}$. 
and desorption on Pt surface would take place rapidly. On the other hand, the formation and reduction of PtO would ocurr slowly and therefore the quantity of electricity for the reaction largely depends on the amount of water molecules. Counting the charge for formation of PtO in $1 \mathrm{M} \mathrm{H}_{2} \mathrm{SO}_{4}$ to be 1 , the value is 0.96 and 0.75 in 30 and $85 \mathrm{wt} \% \mathrm{H}_{3} \mathrm{PO}_{4}$, respectively.

\subsection{Consumption of $P t$ with time, $V_{\text {corr }}$}

Figure 3 shows the amount of consumption of $\mathrm{Pt}$ with time in 60 and 85 wt\% $\mathrm{H}_{3} \mathrm{PO}_{4}$ solutions. The amount of consumption increased with time and the relation is in the first order. From the data, the rate of consumption, $V_{\text {corr }}$ can be obtained by deviding the amount of consumption by time.

$$
V_{\text {corr }}=(\text { the amount of consumption }) / t
$$

The rate in the $60 \mathrm{wt} \%$ solution is almost the same order of the one obtained in $1 \mathrm{M} \mathrm{H}_{2} \mathrm{SO}_{4}$ solution ${ }^{3)}$. However, the value is extraordinary larger in the 85 wt\% solution.

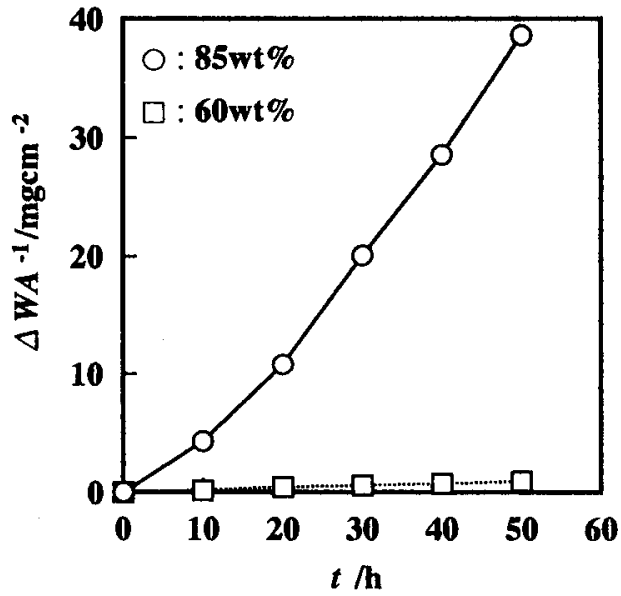

Fig. 3 Relation between weight loss and time at $40^{\circ} \mathrm{C}, 1 \mathrm{Acm}^{-2}$.

\subsection{Consumption of Pt at different concentration of $\mathrm{H}_{3} \mathrm{PO}_{4}$}

Figure 4 shows the consumption in $30-85 w t \%$ phosphoric acid under the electrolysis at $1 \mathrm{Acm}^{-2}$ for $40 \mathrm{~h}$. At the concentration of less than $70 \mathrm{wt} \%$, the amount of consumption was as small as in the sulfuric acid solution as shown above and the red brown $\mathrm{Pt}$ oxide was found on the surface of the electrodes. Figure 5 shows a SEM photograph of the Pt surface

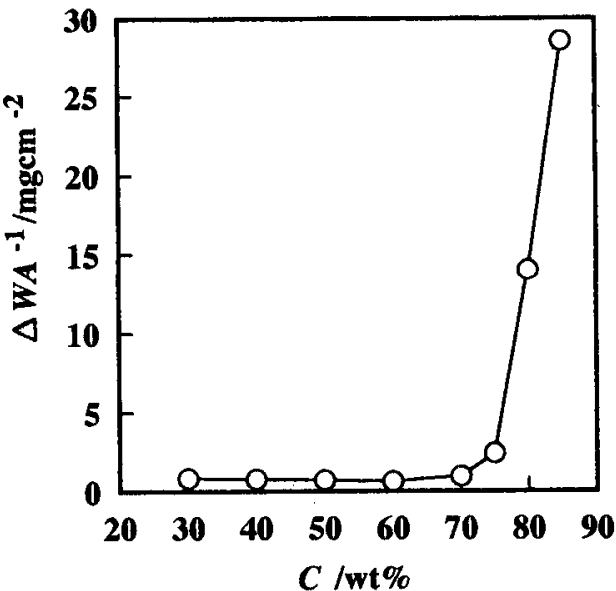

Fig. 4 Relation between weight loss and concentration of phosphoric acid after electolysis for $40 \mathrm{~h}$ at $40^{\circ} \mathrm{C}, 1 \mathrm{Acm}^{-2}$.

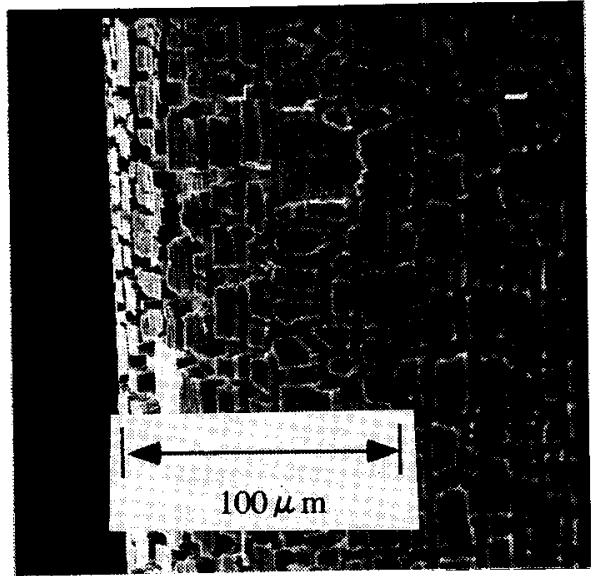

Fig. 5 SEM photograph of Pt surface after electrolysis for $50 \mathrm{~h}$ in $30 \mathrm{wt} \%$ phosphoric acid at $1 \mathrm{Acm}^{-2}$.

taken under electrolysis for $40 \mathrm{~h}$ in the $30 \mathrm{wt} \% \mathrm{H}_{3} \mathrm{PO}_{4}$. It looks like the dried mud swamp and the shingle shaped pieces was partially stripped. These oxide pieces were soluble in the hot $\mathrm{HCl}$ solution and the amount of the $\mathrm{Pt}$ included in the oxide was determined by the spectroscopic method. The amount of $\mathrm{Pt}$ in the $\mathrm{Pt}$ oxide was about $60 \%$ in the total amount of consumption.

The amount of consumption increased urgently as the concentration was raised higher than $70 \mathrm{wt} \%$. On the contrary, the amount of $\mathrm{Pt}$ oxide became smaller with increase of the concentration and no Pt oxide was observed in $85 \mathrm{wt} \%$ solution. In the lower concentration than $70 \mathrm{wt} \%$, the oxide layer would take 
part in to protect the surface from corrosion. In the concentrated phosphoric acid solution, however, the bare $\mathrm{Pt}$ surface is faced to the severe corrosive condition. In this case, the amount of Pt consumption reached as much as $30 \mathrm{mgcm}^{-2}$. After $40 \mathrm{~h}$ electrolysis in $85 \mathrm{wt} \% \mathrm{H}_{3} \mathrm{PO}_{4}$, the electrode got clearly thinner and the solution was contaminated with black particles. First stage of the corrosion would be dissolution into the solution as ions or soluble complexes. The Pt ionsphosphate complex and its solubility are at the present time unknown. Although the discussion is not beyond the speculation, the first stage of the corrosion should be caused by the high solubility of $\mathrm{Pt}$ ions or their complexes.

As shown in the above voltammograms, the electricity for PtO formation decreased with increase of the concentration of phosphoric acid. This decrease would be due to the decrease of the amount of free water molecules. The formation of $\mathrm{PtO}$ that is shown in the voltammograms in Fig. 1 is just the absorption of oxygen onto the surface of $\mathrm{Pt}$ and this layer should be one or two layers from the calculation of electricity. In the prolonged electrolysis, the multilayer, highly oxidized Pt oxide would form if the enough water molecules are present on the Pt surface. In the concentrated $\mathrm{H}_{3} \mathrm{PO}_{4}$, the formation of the oxide layer would be retarded by lack of water molecules.

In the diluted surfuric acid solution, the $\mathrm{Pt}$ oxide layer was also found ${ }^{8,9)}$ under the same electrolysis as shown above. However, when the electrolysis was carried out in the sulfuric acid solution that includes a small amount of organic materials, such as acetonitrile, the oxide layer was not observed9). And the amount of the consumption was extraordinary raised 10 ) just as in the concentrated phosphoric acid (Table 1). When the surface of $\mathrm{Pt}$ is not covered with protective oxide, the bare Pt surface would be faced to the severe corroding condition. Like in the case of the concentrated phosphoric acid, the first stage of the corrosion should be forming and dissolution of $\mathrm{Pt}$ ions or soluble $\mathrm{Pt}$ complex rather than forming the $\mathrm{Pt}$ oxide layer. In the presence of acetonitrile, cyanide ion was formed by the electrolysis ${ }^{91}$. Cyanide ion is a good complexing ligand and would take part in the acceleration of the consumption of Pt. Table 1 shows the rate of consumption, $V_{\text {corr }}$ of $\mathrm{Pt}$ anode in the various electrolytes. In $85 \mathrm{wt} \% \quad \mathrm{H}_{3} \mathrm{PO}_{4}$ solution, no such acceleration by acetonitrile was observed. Once the $\mathrm{Pt}$ surface is uncovered with protective $\mathrm{Pt}$ oxide layer, the formation and dissolution of Pt ions would
Table 1 Rate of consumption ( $\left.V_{\text {corr }}\right)$ of $P t$ anode in various electrolytes at $1 \mathrm{Acm}^{-2}, 40^{\circ} \mathrm{C}$.

\begin{tabular}{|c|c|}
\hline Electrolyte & $V$ corrt $\mu$ gcm-2h-1 $^{-1}$ \\
\hline $85 W t \% \mathrm{H}_{3} \mathrm{PO}_{4}$ & 910 \\
\hline $\begin{array}{l}85 W \mathrm{t} \% \mathrm{H}_{3} \mathrm{PO}_{4} \\
+0.5 \mathrm{MCH}_{3} \mathrm{CN}\end{array}$ & 740 \\
\hline $30 \mathrm{Wt}_{2} \mathrm{H}_{3} \mathrm{PO}_{4}$ & 19 \\
\hline $1 \mathrm{M} \mathrm{H}_{2} \mathrm{SO}_{4}$ & 5 \\
\hline $1 \mathrm{M} \mathrm{H} \mathrm{H}_{2} \mathrm{SO}_{4}+1 \mathrm{MCH}_{3} \mathrm{CN}$ & 750 \\
\hline $1 \mathrm{M} \mathrm{NaOH}$ & 0.5 \\
\hline $1 \mathrm{M} \mathrm{NaOH}+1 \mathrm{MCH}_{3} \mathrm{CN}$ & 780 \\
\hline
\end{tabular}

proceed fast. The effect of acetonitrile was also observed in alkaline solution such as $\mathrm{NaOH}$ solution. The discussion shall be made in another report later.

Figure 6 shows the amount of consumption of $\mathrm{Pt}$ in $85 \mathrm{wt} \%$ phosphoric acid with time up to $120 \mathrm{~h}$. It increased with time almost linearly. The rate of consumption, i.e., the amount of consumption devided by time, $V_{\text {corr }}$ at 20 to $50 \mathrm{~h}$ after the start of electrolysis was $0.91 \mathrm{mgcm}^{-2} \mathrm{~h}-1$. However, the precise observation showed the rate of consumption at the start of electrolysis was slightly larger than that observed at the steady state (after ca. 20h). In this initial stage, the bright surface of Pt became gradually rough. And the rate of consumption gradually

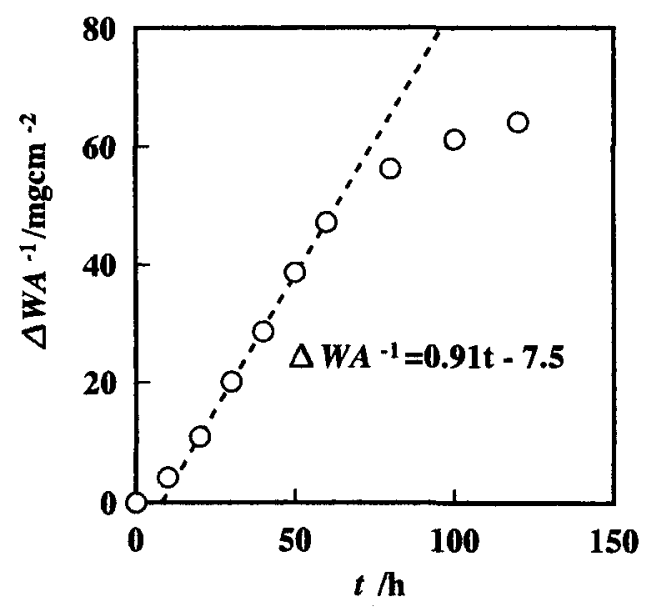

Fig.6 Relation between weight loss and time at $40^{\circ} \mathrm{C}, 1 \mathrm{Acm}^{-2}$ in $85 \mathrm{wt} \% \mathrm{H}_{3} \mathrm{PO}_{4}$. 
decreased with time after $60 \mathrm{~h}$. In this stage, the total amount of consumed $P t$ reached to about $1 / 3$ of the initial Pt weight. Since the geometrical surface area is related to the square root of the weight, the change of weight at the shorter time period is small and does not give serious effect on the corrosion mehcanism. However, after $60 \mathrm{~h}$, the weight change was huge and the geometrical surface area should have been smaller than that of the initial stage by $20 \%$ and also the solution was contaminated with dissolved $\mathrm{Pt}$ species. The consumption curve may not be elucidated with the simple mechanism.

\subsection{Dependence of Pt consumption on the current density}

The $V_{\text {corr }}$ observed in the $30 w t \%$ phosphoric acid, $1 \mathrm{M}$ sulfuric acid and $1 \mathrm{M} \mathrm{NaOH}$ solutions ${ }^{11)}$ was summerized in Table 1 . The value in $85 w t \%$ is about 180 times as large as the one in sulfuric acid solution, and 1800times larger than the one in $\mathrm{NaOH}$ solution.

Figure 7 shows the consumption in $85 \mathrm{wt} \%$ at the current density of $0.2,0.4,0.6,0.8$ and $1 \mathrm{Acm}^{-2}$ up to $50 \mathrm{~h}$. The $V_{\text {corr }}$ was obtained between 20 and $50 \mathrm{~h}$. The relation between $V_{\text {corr }}$ and the current density was plotted in Fig. 8. The $V_{\text {corr }}$ was small under the small current density but it increaed gradually when the current density was raised to $0.6 \mathrm{Acm}^{-2}$ and $V_{\text {corr }}$ got a linear relation to the current density. Assuming all the data fall on the linear relation except at the low current density, the unit consumption of $\mathrm{Pt}$ anode, i.e., $U_{\text {corr }}$ can be obtained by dividing $V_{\text {corr }}$ by current density.

The $U_{\text {corr }}$ of $910 \mu \mathrm{gA}^{-1} \mathrm{~h}^{-1}$ was obtained. This value is

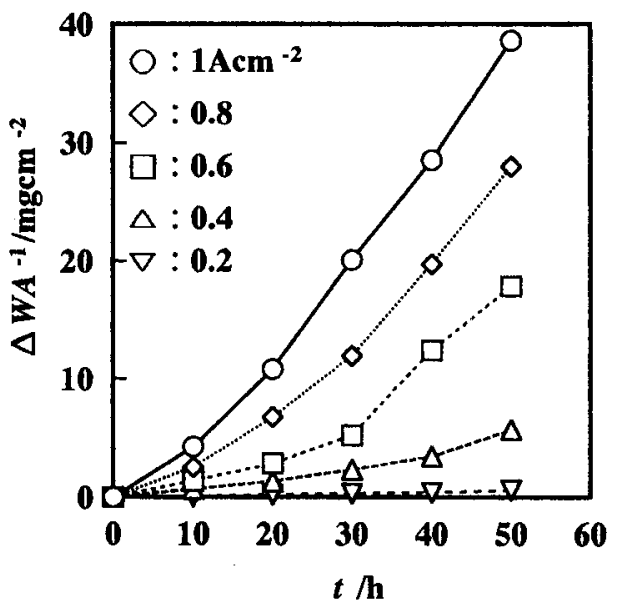

Fig. 7 Relation between weight loss and time at various current densities.

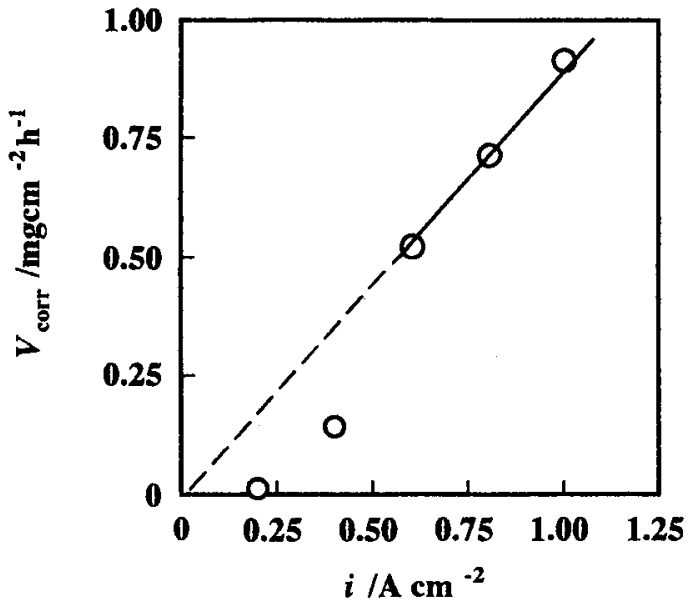

Fig. 8 Average rate of consumption of $\mathrm{Pt}$ anode in 85 wt \% phosphoric acid between 20 and $50 h$.

density operated at the high current density. The mechanism of consumption at the high current density may be different from those at the low current density.

\subsection{Tafe's plots}

Figure 9 shows the Tafel's plots of Pt anode in 30 and $85 \mathrm{wt} \%$ phosphoric acid solution. Under the current density of less than $0.1 \mathrm{Acm}^{-2}$, the slopes for both concentration are almost the same and the Tafel's coefficient is about $120 \mathrm{mV}$ that is larger than that obtained in sulfuric acid solution ${ }^{3)}$ i.e., $90 \mathrm{mV}$ and the mechanism in this case may be different from that in sulfuric acid solution. The number of electrons in the

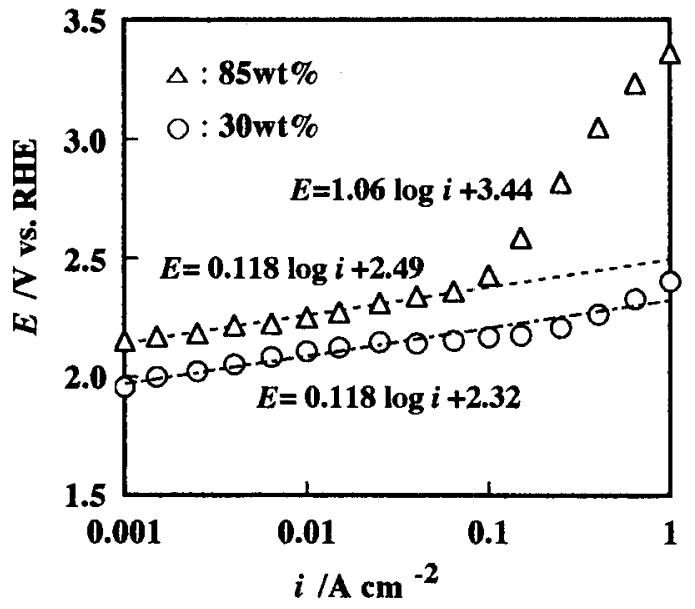

Fig. 9 Tafel plots of Pt anode in 30 and 85 wt\% phosphoric acid at $40^{\circ} \mathrm{C}$. 
rate determining step and the transfer coefficient would be 1 and 0.5 are expected, respectively. In $85 \mathrm{wt} \%$ phosphoric acid solution, the slope extremely increased under the current density of larger than $0.1 \mathrm{Acm}^{-2}$. The slope is too large to be elucidated by the general charge transfer mehcanism. This may be due to the insufficient water transfer in the $85 \mathrm{wt} \%$ solution under the higher current density.

As shown in Fig. 8, the linear relation between Vcorr and $i$ (current density) was assumed and from these data, the following equation was derived.

$$
V_{\text {corr }}=\mathbf{k} i
$$

where $k$ is the constant and in this case, $k$ is nearly equally to 1 . Utilizing this equation, the relation between the potential, $\mathrm{E}$ and the current density, $i$ can be replaced by

$$
E=2.49+0.118 \log V_{\text {corr }}
$$

for the lower current density region in $85 \mathrm{wt} \%$ phosphoric acid solution and

$$
E=3.44+1.06 \log V_{\text {corr }}
$$

for the higher current density region.

If the $U_{\text {corr }}$ is constant, the time for consumption of $1 \mathrm{mg} \mathrm{Pt}$ should be $1 / V_{\text {corr }}$. Therefore, from the equations (3) and (4), the time can be determined. These relations may not be applied directly to the actual case for the fuel cell electrodes or other corrosion mechanism. Anyhow, if the $\mathrm{Pt}$ is placed under a certain potential the Vcorr would be derived by the above relationship.

\section{CONCLUSION}

In the phosphoric acid solution of which concentration is lower than $70 \mathrm{wt} \%$, the $\mathrm{Pt}$ anode was protected by the Pt oxide that formed on the surface under the long time electrolysis and the amount of degraded Pt was as little as in the sulfuric acid solution. However, as the concentration was raised higher than $70 \mathrm{wt} \%$, the oxide layer becomes thinner and the amount of dissolution of Pt increased rapidly. This enormous dissolution would be due to the large solubility product of the complex between the dissolved Pt ion species and phosphoric acid ligand, and therefore, it would be difficult to form the protective oxide layer on the surface of the Pt anode. The rate of corrosion, $V_{\text {corr }}$ of $\mathrm{Pt}$ anode in the concentrated phosphoric acid solution, was $0.91 \mathrm{mgcm}^{-2} \mathrm{~h}^{-1}$ and this value was 180 and 1800 times as large as in the $1 \mathrm{M}$ sulfuric acid and $1 \mathrm{M}$ alkaline solutions.

The operating condition of the cathode in the practical phosphoric fuel cell is a little different from those in this experiment. However, the extrapolation of the data, e.g., Tafel's plots, to the practically operated condition, would be helpful to clear the mechanism of the degradation of the Pt catalyst.

\section{References}

1) M. Toson, K. Shiraki, Y. Usami and T. Takae, 4th FCDIC Fuel Cell Symposium Proceedings, p. 1 (1997).

2) M. Watanabe, K. Tsurumi, T. Mizukami, T. Nakamura and P. Stonehart, J. Electrochem. Soc., 141, 2659 (1994).

3) K. Ota, S. Nishigori and N. Kamiya, J. Electroanal. Chem., 257, 205 (1988).

4) L. D. Burke, Electrodes of Conductive Metallic Oxides (Ed. S.Trasatti), Part B, Elsevier Scientific Publishing Co., Amsterdam, p.143 (1980).

5) E. Passalacqua, P.L. Antonussi, M. Vivaldi, A. Patti, N. Giordano and K. Kinoshita, Proc. 27th Intersoc. Energy Convers. Eng. Conf. Vol. 3, 3-425 (1992).

6) M.Miyamoto, Japan Analyst, 9, 925 (1960).

7) M. Kawabata, H. Mochizuki and T. Misaki, Japan Analyst, 11, 819, 1020 (1962).

8) S. Kajiwara, Masters thesis of Yokohama National University (1985).

9) S. Aihara, Masters thesis of Yokohama National University (1992).

10) M. Takahashi, SODA \& CHLORINE, 47, 137 (1996).

11) X.J.Huang, Masters thesis of Yokohama National University (1996). 